\title{
Hubungan antara Fleksibilitas Sumber Daya, Modal Psikologis dan Perilaku Kerja Inovatif
}

\author{
Lalita Maitri, Debora Eflina Purba
}

Fakultas Psikologi, Universitas Indonesia, Depok 16424, Indonesia

email: lalita.maitri@gmail.com

\begin{abstract}
Abstrak
Penelitian ini bertujuan untuk mengetahui efek mediasi modal psikologis pada fleksibilitas sumber daya dan perilaku inovatif di tempat kerja. Sampel diambil dari 150 karyawan di kantor pusat sebuah perusahaan asuransi di Jakarta, dan dianalisis menggunakan teknik regresi dari macro SPSS. Analisis korelasi menunjukkan bahwa terdapat korelasi yang positif dan signifikan antara fleksibilitas sumber daya dan perilaku inovatif di tempat kerja $(r=0.714, p<0.01)$. Analisis korelasi antara fleksibilitas sumber daya dengan modal psikologis menunjukkan korelasi yang positif $(r=0.635, p<0.01)$. Korelasi positif juga ditunjukkan hubungan antara modal psikologis dengan perilaku inovatif di tempat kerja $(r=0.845, p<0.01)$. Hasil analisis regresi menggunakan Process Hayes menunjukkan bahwa modal psikologis berperan sebagai mediator secara parsial pada hubungan antara fleksibilitas sumber daya dan perilaku kerja inovatif.
\end{abstract}

Kata kunci: perilaku kerja inovatif, fleksibilitas sumber daya, modal psikologis

\section{Correlation between Human Resource Flexibility, Psychological Capital and Innovative Work Behaviour}

\begin{abstract}
This study aims to determine the mediation effect of psychological capital on human resource flexibility and innovative work behavior. Data were taken from 150 employees of an insurance company in Jakarta and were analyzed using regression technique on SPSS software. The results show that there is a positive and significant correlation between human resource flexibility and innovative work behavior $(r=0.714, p<0.01)$, positive correlation between resource flexibility and psychological capital $(r=0.635$, $p<0.01$ ) and a positive correlation between psychological capital and innovative work behavior $(r=0.845, p<0.01)$. The result of regression analysis using Process Hayes shows that psychological capital acts as a mediator partially on relationship between resource flexibility and innovative work behavior.
\end{abstract}

Keywords: innovative work behavior, human resource flexibilitly, psychological capital

\section{Pendahuluan}

Perkembangan teknologi dewasa ini telah mengubah berbagai aspek kehidupan manusia, mulai dari gaya hidup sampai kegiatan berbisnis. Perubahan menjadi perlu dilakukan organisasi untuk meningkatkan efektifitas dengan tujuan mengupayakan perbaikan kemampuan organisasi (Robbins, 2015). Salah satu strategi yang efektif bagi organisasi agar dapat tetap eksis dan efektif untuk memainkan peranannya di tengah maraknya kompetisi adalah melalui inovasi organisasi (Budihardjo, 2016).

Penelitian ini dilakukan pada PT XYZ yang memiliki visi misi inovasi. PT XYZ sebagai salah satu Badan Usaha Milik Negara yang diberi tugas oleh Pemerintah untuk penyelenggaraan dan pengelolaan program asuransi sosial dan dana pensiun Aparatur Sipil Negara juga menjadi mutlak mewujudkan peningkatan kualitas pelayanan. Salah satu ancaman terkini yang yang sedang dihadapi oleh PT XYZ adalah peleburan PT Asabri dan PT XYZ ke BPJS Ketenagakerjaan yang tercantum dalam undang-undang UU 40 / 2000 Pasal 5 ayat (2) tentang Sistem Jaminan Sosial Nasional (SJSN). Ancaman ini membawa PT XYZ masuk ke dalam sebuah burning platform untuk melakukan perubahan. Upaya awal yang dilakukan oleh PT XYZ adalah perusahaan menetapkan perubahan nilai. Inovasi merupakan salah satu nilai-nilai baru PT XYZ yang menuntut untuk meningkatkan 
pelayanan dan mencari pendekatan baru guna memenuhi kebutuhan pelanggan.

Inovasi di organisasi mengacu pada

bakat dan kreativitas yang datang dari individu-individu di organisasi dalam proses menemukan ide atau solusi baru dalam menyelesaikan masalah (Kanter, 1988). Perilaku individu-individu yang ada di organisasi untuk terlibat membuat perubahan menentukan kemunculan ide inovatif di organisasi tersebut (Kanter, 1988). Perilaku kerja inovatif (innovative work behavior) didefinisikan sebagai upaya terencana individu dalam perilaku inovatif, yang mencakup pembangkitan ide, promosi gagasan dan realisasi gagasan, dengan tujuan menghasilkan inovasi (Janssen, 2000)

Penelitian-penelitian sebelumnya menunjukkan berbagai faktor internal (individu) dan faktor eksternal (lingkungan) berperan sebagai penyebab perilaku kerja inovatif individu. Contoh faktor internal adalah perbedaan karakteristik individu, dan faktor demografi (Anderson et al., 2004, Shalley \& Gilson, 2004). Kemampuan kognitif, keahlian, pengetahuan pada tugas, keterampilan teknis, karakteristik kepribadian, motivasi dan kepuasan (Woodman et al., 1993; Collins \& Amabile, 1999; Weisburg, 1999; Ford 2000). Faktor internal lainnya Fleksibilitas dan preferensi untuk perubahan dan hal baru (Georgsdottir \& Getz, 2004) dan faktor-faktor psikologis (psychological factors) yang mendorong individu untuk bertahan dalam menghadapi tantangan kerja yang kreatif (Shalley \& Gilson 2004).

Sementara itu, faktor eksternal yang mempengaruhi perilaku kerja inovatif adalah pekerjaan yang dinamis (Amabile \& Gryskiewicz, 1987; Van der Vegt \& Janssen, 2003), komposisi tim yang beragam dalam keterampilan dan pengetahuan, atau keanekaragaman fungsional (Keller, 2001; Paulus, 2000; West \& Hirst, 2003), struktur, ukuran dan kompleksitas organisasi (Baldrige \& Burnham, 1975; Damanpour \& Gopalakrishnan, 1998; Subramanian \& Nilakanta, 1996).

Salah satu faktor eksternal yang mempengaruhi perilaku kerja inovatif adalah organizational flexibility (fleksibilitas organisasi) yang meliputi human resource flexibility (fleksibiltas Manajemen Sumber Daya
Manusia) (Dorenbosch, Engen \& Verhagen, 2005; Jiménez-Jiménez \& Sanz-Valle, 2008; Martinez-Sánchez, Vela-Jiménez, PérezPérez, \& de-Luis-Carnicer, 2011) dan individual flexibility (fleksibilitas individu) (Oldham \& Cummings, 1996). Penelitian ini berfokus pada fleksibilitas SDM sebagai faktor yang mempengaruhi perilaku kerja inovatif, karena manajemen sumber daya manusia yang fleksibel dalam sistem dan proses membantu organisasi menyesuaikan diri dengan perubahan lingkungan, dan membuka jalan munculnya keinginan individu untuk berinovasi (Bhattacharya, Gibson, \& Doty, 2005). Fleksibilitas SDM didefinisikan sebagai persepsi karyawan pada kemampuan Manajemen SDM (untuk selanjunta disingkat SDM) memberi alternatif strategis menghadapi persaingan perusahaan, dan juga sejauh mana praktik manajemen SDM dapat memaksimalkan kemampuan dan potensi individu (Wright \& Snell, 1998).

Penelitian sebelumnya menunjukkan koefisien korelasi antara fleksibilitas SDM terhadap perilaku kerja inovatif tergolong rendah (Do, Yeh, \& Madsen, 2016; Veenendaal \& Bondarouk, 2015; Wojtczuk-Turek, Agniezka \& Turek, 2015). Wojtczuk dkk. (2015) menemukan fleksibilitas SDM berpengaruh pada perilaku kerja inovatif lewat psychological capital (modal psikologis). Modal psikologis didefinisikan oleh Luthans, Youssef, dan Avolio (2007) adalah kondisi psikologis seseorang yang positif yang dicirikan menjadi 4 sumber daya psikologis, yaitu self efficacy (kemampuan dan kepercayaan diri), hope (harapan), optimism (optimis) dan resilience (ketahanan). Beberapa penelitian membuktikan pentingnya modal psikologis sebagai anteseden yang sangat kuat mempengaruhiperilaku kerja inovatif (Ziyae, 2015; Sameer, 2014).

Wojtczuk dkk. (2015) melakukan penelitian di Polandia dari dua data sumber berbeda. Pertama penelitian dilakukan atas dasar kuesioner internet. Kedua penelitian dilakukan pada 70 siswa berprestasi dalam program pascasarjana di Sekolah Ekonomi Warsawa. Hasil penelitian tersebut terungkap fleksibilitas praktik SDM mempengaruhi 
perilaku kerja inovasi, secara tidak langsung. Penelitian menunjukkan bahwa modal psikologis adalah mediator dari hubungan ini. Penelitian ini merupakan replikasi dari penelitian Wojtczuk dkk. (2015). Peneliti berpendapat Indonesia memiliki karakteristik yang berbeda dengan sampel penelitian terdahulu di Polandia, yaitu Indonesia memiliki budaya kolektif (Hofstede, 2005). Penelitian ini dilakukan pada konteks perusahaan Badan Usaha Milik Negara (BUMN), karena image BUMN sebagai perusahaan yang birokratis, kurang fleksibel, perlu perbaikan layanan publik dan minim inovasi. Peneliti berargumentasi bahwa praktik-praktik SDM yang fleksibel dapat meningkatkan harapan individu (hope) bahwa usaha yang akan dilakukan tidak dihambat oleh aturan yang kaku. Fleksibilitas SDM juga meningkatkan efikasi diri individu karena individu dapat melakukan job crafting tanpa merasa takut dihambat oleh aturan SDM, meningkatkan optimisme individu karena aturan SDM yang fleksibel mampu mengidentifikasi kemampuan mereka. Fleksibilitas SDM meningkatkan resiliensi diri individu dalam menghadapi masalah dalam pekerjaannya karena individu diberikan keleluasaan dalam menangani masalah tanpa perasaan takut pada konsekuensi kegagalan kerja. Peningkatan dalam efikasi diri, harapan, optimisme, dan resiliensi diri akan berpengaruh positif pada perilaku inovasi kerja. Dalam hal ini, ketika individu merasa kemampuannya meningkat, memiliki harapan dan optimism yang besar dalam pekerjaannya, dan mampu bangkit dari kegagalannya dengan cepat sehingga menganggap kegagalan bukan sesuatu yang perlu dihindari, maka ia akan mampu menghasilkan ide yang cemerlang dan berani mempromosikan ide tersebut agar dapat diterima oleh organisasi.

Dengan demikian hipotesis yang akan diuji dalam penelitian ini adalah adanya peran modal psikologis sebagai mediator hubungan antara fleksibilitas sumber daya dengan perilaku inovatif karyawan.

\section{Metode}

Penelitian ini menggunakan metode survei dimana data diambil secara self-reported. Teknik statistik yang digunakan untuk pengujian pada hipotesis penelitian adalah analisis mediasi Macro PROCESS dari Hayesdengan bantuan SPSS (Statistical Package for the Social Science) versi 21.0.

\section{Partisipan}

Responden penelitian adalah karyawan di PT XYZ yang sudah bekerja di perusahaan selama minimal 1 tahun, berstatus karyawan tetap, dan berasal dari level manajerial dan non-manajerial dari semua divisi di kantor pusat PT XYZ.

Kuesioner yang disebarkan ke perusahaan sejumlah 404 eksemplar.Kuesioner yang kembali kepada peneliti adalah 150 eksemplar (response rates $37 \%$ ). 
Tabel 1 Gambaran Karakteristik Partisipan

\begin{tabular}{lcc}
\hline Karakteristik & $\begin{array}{c}\mathbf{N} \\
\text { (Jumlah) }\end{array}$ & Persentase \\
\hline Jenis Kelamin & 58 & \\
Perempuan & 92 & $38.7 \%$ \\
Laki-Laki & 150 & $61.3 \%$ \\
Total & & $100 \%$ \\
Usia & 58 & \\
$\leq 29$ tahun & 44 & $38.7 \%$ \\
$30-49$ tahun & 48 & $29.3 \%$ \\
Di atas 50 tahun & 150 & $32.0 \%$ \\
Total & & $100 \%$ \\
Pendidikan & 26 & \\
SMA & 26 & $17.3 \%$ \\
Diploma & 82 & $17.3 \%$ \\
Strata 1 & 16 & $54.7 \%$ \\
Strata 2 & 96 & $10.7 \%$ \\
Total & & $100 \%$ \\
Masa Kerja & 10 & \\
1 bulan - 1 tahun & 41 & $6.7 \%$ \\
2 tahun- 11 tahun & 16 & $50.7 \%$ \\
26- 29 tahun & 23 & $15.3 \%$ \\
Di atas 30 tahun & 150 & $100 \%$ \\
Total &
\end{tabular}

Berdasarkan usia yang dikelompokkan dalam kaitannya dengan produktivitas karyawan, peneliti membagi usia menjadi tiga kategori yaitu young ( $\leq 29$ tahun), middle aged (30-49 tahun), dan older ( $\geq 50$ tahun) (Cataldi \& Rycs, 2012). Sebagian besar responden berada dalam rentang usia $\leq 29$ tahun (38.7\%). Jumlah responden laki-laki lebih banyak $(61.3 \%)$ dibandingkan dengan jumlah responden perempuan (38.7\%). Pada data latar belakang pendidikan, sebagian besar responden memiliki jenjang pendidikan Strata $1(54.7 \%)$, kemudian lainnya adalah lulusan Diploma 3 (17.3\%), SMA (17.3\%), dan lulusan Strata $2(10.7 \%)$. Terakhir didapatkan data bahwa sebagian besar responden sudah bekerja di atas 2 tahun - 11 tahun (78.1\%). Pembagian kelompok masa kerja dibagi berdasarkan empat kategori yaitu calon pegawai (1 bulan -1 tahun), tahap perkembangan (2 - 11 tahun), tahap lanjutan (26 - 29 tahun), tahap maturity (di atas 30 tahun). Terdapat selisih masa kerja yang cukup jauh dari tahap lanjutan ke tahap perkembangan karena pada tahun 1991 hingga tahun 2005 PT XYZ tidak melakukan rekrutmen pegawai sehingga terjadi kesenjangan generasi.

\section{Pengukuran}

Alat ukur fleksibilitas SDM dan modal psikologis merupakan alat ukur berbahasa Inggris yang diterjemahkan ke dalam Bahasa Indonesia menggunakan prosedur back translation. Skala Perilaku Kerja Inovatif dari Janssen yang diadaptasi oleh Etikariena dan Muluk (2014) ke dalam Bahasa Indonesia.

Skala Fleksibilitas SDM merupakan adaptasi Human Resource Practice Flexibility Scale dari Ketkar dan Sett (2009) yang terdiri dari 7 item. Contoh itemnya adalah "praktik manajemen SDM di perusahaan cukup fleksibel membantu kami menyesuaikan diri dengan perubahan lingkungan yang kompetitif". Alat ukur ini menunjukkan alat ukur yang relaibel dengan hasil uji menggunakan Alfa Cronbach menunjukan hasil perhitungan berkisar dari 0.903 hingga 0.951 .

Psychological Capital Questionaire merupakan skala yang terdiri dari 24 item dan 4 komponen yaitu yaitu efficacy, hope, opti- 
mism dan resilience. Contoh itemnya adalah "saya mampu menemukan solusi bagi masalah yang bersifat jangka panjang". Hasil uji reliabilitas menggunakan Alfa Cronbach menunjukan alat ukur cukup reliabel dengan hasil perhitungan reliabilitas sebesar 0.985

Skala Perilaku Inovatif di tempat kerja terdiri dari 9 item dan 3 dimensi yaitu idea generalization, idea promoting dan idea realization.Contoh itemnya adalah "membuat pimpinan saya antusias dengan ide-ide baru yang saya sampaikan". Hasil uji reliabilitas menggunakan Alfa Cronbach menunjukkan alat ukur yang realiabel, dengan hasil perhitungan reliabilitas berkisar dari 0,756-0,945,

\section{Hasil}

\section{Uji Deskriptif}

Tabel 1 merupakan Statistik deskriptif skala Perilaku Kerja Inovatif, Modal Psikologis dan Fleksibilitas SDM. Tabel ini menunjukkan bahwa partisipan secara keseluruhan memiliki perilaku kerja Rata-rata dari total skor perilaku kerja inovatif memiliki skor minimum 2 dan skor maksimum 6 dengan mean 4.65 dan standar deviation (SD) 0.79. Skor minimal fleksibilitas SDM yang dapat diperoleh adalah 1.86 dan skor maksimal 6 dengan mean 4.3 dan SD 1.01. Sedangkan skor modal psikologis minimal yang dapat diperoleh adalah 1.08 dan skor maksimal adalah 6.0. Berdasarkan hasil pengolahan data, mean yang diperoleh adalah 4.84 dan SD 0.92 .

Tabel 2. Statistik Deskriptif Variabel Penelitian

\begin{tabular}{lllll}
\hline Variabel & Mean & Min & Max & SD \\
\hline Perilaku Kerja Inovatif & 4.65 & 2 & 6 & .79 \\
Modal Psikologis & 4.84 & 1.08 & 6 & .92 \\
Fleksibilitas SDM & 4.3 & 1.86 & 6 & 1.01 \\
\hline
\end{tabular}

Uji Korelasi

Pada tabel 2 korelasi Pearson Product Moment diperoleh hasil bahwa fleksibilitas SDM memiliki hubungan positif dengan perilaku kerja inovatif $(r=0.714$, $p<0.01)$. Selain itu juga didapatkan hasil bahwa fleksibilitas SDM berhubungan dengan modal psikologis $(r=0.635, p<$ 0.01). Terakhir, hasil menunjukkan bahwa modal psikologis berhubungan dengan perilaku kerja inovatif $(r=0.845, p<0.01)$.
Hal ini menunjukkan bahwa terdapat hubungan antara modal psikologis dan perilaku kerja inovatif pada karyawan kantor pusat PT XYZ yang bersifat positif, dengan kata lain semakin tinggi tingkat modal psikologis maka akan meningkatkan tingkat perilaku kerja inovatif. Hal ini menunjukkan bahwa semakin tinggi tingkat fleksibilitas SDM maka akan juga meningkatkan tingkat modal psikologis. 
Tabel 3. Hasil Uji Korelasi Variabel Demografis dengan Variabel Perilaku Inovatif Karyawan dan Memori Organisasi

\begin{tabular}{llllll}
\hline & $\mathbf{1}$ & $\mathbf{2}$ & $\mathbf{3}$ & $\mathbf{4}$ & $\mathbf{5}$ \\
\hline 1. HR flexibility & 1 & & & & \\
2. Psychological capital & $.635^{* *}$ & 1 & & & \\
3. Innovative work behaviour & $.714^{* *}$ & $.845^{* *}$ & 1 & & \\
4. Pendidikan & -.177 & -.038 & -.103 & NA & \\
5. Usia & .054 & -.052 & .032 & $.167^{*}$ & NA \\
\hline
\end{tabular}

$\mathrm{N}=150$

$\mathrm{NA}=$ not applicable.

Angka pada diagonal menunjukkan koefisien reliabilitas alat ukur penelitian.

$\left.{ }^{* *}\right)$ signifikan pada level 0.01 (2-tailed).

*) signifikan pada level 0.05 (2-tailed)

Uji Analisis Macro PROCESS Hayes

Setelah diketahui hasil uji korelasi tersebut, barulah dilakukan analisis Macro PROCESS Hayes (2012) ditujukan untuk mengukur besaran pengaruh (effect size) dari pengaruh tidak langsung (indirect effect) Hasilnya terangkum dalam Tabel 3.

Hasil analisis Mediasi Proses Hayes pengaruh langsung fleksibilitas SDM terhadap perilaku kerja inovatif (direct effect) tetap signifikan (effect $=.2202$,
$\mathrm{SE}=.0498,95 \% \mathrm{Cl}[.1376, .3028])$ setelah modal psikologis masuk ke dalam model sebagai mediator. Oleh karena pengaruh tidak langsung (indirect effect) fleksibilitas SDM terhadap perilaku kerja inovatif melalui modal psikologis signifikan (effect $=$ $.3471, \mathrm{SE}=.0435,95 \% \mathrm{Cl}[.2589,4572])$ maka dapat disimpulkan bahwa modal psikologis berperan sebagai mediator secara parsial pada hubungan antara fleksibilitas SDM dan perilaku kerja inovatif.

Tabel 3. Modal Psikologis sebagai Mediator pada Hubungan antara Fleksibilitas SDM dan Perilaku Kerja Inovatif

\begin{tabular}{lllrlll}
\hline & Effect & SE & \multicolumn{1}{c}{ T } & P & LLCl & ULCI \\
\hline Total Effect & .5672 & .0418 & 12.1874 & .0000 & .4753 & .6592 \\
Direct Effect & .2202 & .0498 & 5.2683 & .0000 & .1376 & .3028 \\
Indirect Effect & .3471 & .0435 & .0000 & .2589 & .4572 &
\end{tabular}

\section{Pembahasan}

Berdasarkan hasil uji korelasi berarti bahwa semakin tinggi tingkat fleksibilitas SDM maka akan semakin meningkatkan perilaku kerja inovatif. Hal ini pun menyatakan bahwa terdapat hubungan antara fleksibilitas SDM dan modal psikologis pada karyawan kantor pusat bersifat positif. Ini menunjukkan bahwa semakin tinggi tingkat fleksibilitas SDM maka akan juga meningkatkan tingkat modal psikologis.
Hasil tes mediasi menggunakan Macro Process Hayes, menunjukkan modal psikologis berperan sebagai mediator secara parsial pada hubungan antara fleksibilitas SDM dan perilaku kerja inovatif. Hal ini berarti terdapat sebagian peran modal psikologis sebagai mediator pada hubungan antara fleksibilitas SDM dan perilaku kerja inovatif pada karyawan kantor pusat PT XYZ terbukti dalam penelitian ini. Hal ini sesuai dengan penelitian sebelumnya yang menunjukkan bahwa sistem SDM yang fleksibel mempengaruhi perilaku karyawan secara tidak langsung, terda- 
pat variabel yang berperan sebagai mediator misal sikap karyawan (Wright dkk., 2001), atau Person Organization Fit (Chang dkk., 2010; Boon dkk., 2011).

Sebagai implikasi praktis dari penelitian ini, organisasi dapat menggunakan pelatihan untuk meningkatkan pengetahuan dan keterampilan beradaptasi dengan peran atau aspek kerja baru. Selain itu, pelatihan harus dibarengi dengan pembinaan dan pendampingan untuk dapat menyesuaikan atau mewujudkan pada aspek pekerjaan, pengetahuan dan keterampilan dibangun melalui aktifitas berbagi pengetahuan untuk saling belajar. Aktivitas berbagi pengetahuan akan memperkuat sumber daya kognitif individu serta akumulasidi tingkat tim untuk menghasilkan solusi bagi pekerjaan (Chuang,Jackson, \& Jiang, 2016; Lv \& Xu, 2016; Way dkk., 2015). Lewin dalam (Cameron dan Green, 2012) mengemukakan bahwa proses perubahan menjadi perilaku fleksibel dan inovatif yang terintegrasi dibangun melalui melalui indikator kinerja dan sistem penghargaan.

Penelitian ini memiliki keterbatasan dalam hal-hal pelaksanaan pengambilan data di lapangan. Pertama, teknik accidental sampling menyebabkan peneliti hanya mampu melibatkan 150 karyawan kantor pusat $\mathrm{PT} X Y Z$ sehingga hasilnya belum mewakili keseluruhan karyawan $\mathrm{PT} X Y Z$ kantor pusat juga karyawan di Cabang. Kedua, kemungkinan adanya bias pada hasil penelitian karena penelitian lebih bersifat self report survey yang rentan adanya bias respon individu terhadap pertanyaan yang dikenakan padanya (social desirability). Ketiga, penelitian ini dilakukan dengan desain cross sectional study yang dilakukan hanya dalam sekali waktu sehingga membatasi peneliti untuk memastikan hubungan kausalitas antar variabel penelitian.

\section{Kesimpulan}

Penelitian ini bertujuan untuk mengetahui peran mediasi modal psikologis antara fleksibilitas sumber daya dan perilaku kerja inovatifpada karyawan kantor pusat di peru- sahaan XYZ.

Hasil penelitian menunjukkan modal psikologis berperan sebagai mediator pada hubungan antara fleksibilitas SDM dan perilaku kerja inovatif.

\section{Daftar Pustaka}

Agarwal, U. A. (2014). Linking justice, trust and innovative work behaviour to work engagement. Personnel Review, 43 (1), 41-73.

Amabile, T. M., \& Gryskiewicz, S. S. (1987). Creativity in the R\&D Laboratory. North Carolina. Center for Creativity Leadership.

Anderson, N., De Dreu, C.K.W. and Nijstad, D.A. (2004) The routinization of innovation research: a constructively critical review of the state-of-thescience. Journal of Organizational Behavior, 25, 147-172.

Baldrige, J.V., \& Burnham, R.A. (1975). Organizational innovation: Individual, organizational and environmental impacts. Administrative Science Quarterly, 20(2), 165-176.

Bhattacharya, M., Gibson, D. E., \& Doty, D. H. (2005). The effects of flexibility in employee skills, employee behaviors, and human resource practices on firm performance. Journal of Management, 31 (4), 622-640.

Boon, C., Den Hartog, D. N., Boselie, P., \& Paauwe, J. (2011). The relationship between perceptions of HR practices and employee outcomes: examining the role of person-organisation and person-job fit. The International Journal of Human Resource Management, 22(01), 138-162.

Budihardjo, A. (2016). Knowledge Management. Efektif Berinovasi Meraih Sukses. Jakarta: Prasetiya Mulya Publishing.

Chang, H.T., Chi, N.W. and Chuang, A. (2010), "Exploring the moderating roles of perceived person - job fit and person - organisation fit on the relationship between training investment and 
knowledge workers' turnover intentions", Alied Psychology: an International Review, 59(4), 566-593.

Collins, M.A. and Amabile, T.M. (1999) Motivation and creativity. In R.J. Sternberg (Ed.), Handbook of Creativity (297-312). Cambridge, England: Cambridge University Press.

Chuang, C. H., Jackson, S. E., \& Jiang, Y. (2016). Can knowledge-intensive teamwork be managed? Examining the roles of HRM systems, leadership, and tacit knowledge. Journal of Management, 42, 524-554. doi:10.1177/0149206313478189

Damanpour, F., \& Gopalakrishnan, S. (1998). Theories of organizational structure and innovation adoption: the role of environment change. Journal of Engineering Technology Management, 15, 1-24

Do, B. R., Do, B. R., Yeh, P. W., Yeh, P. W., Madsen, J., \& Madsen, J. (2016). Exploring the relationship among human resource flexibility, organizational innovation and adaptability culture. Chinese Management Studies, 10(4), 657-674.

Dorenbosch, L., van Engen, M.L. and Verhagen, M. (2005), "On-the-job innovation: the impact of job design and human resource management through production ownership", Creativity and Innovation Management, 14 (2), 121-149.

Etikariena, A., \& Muluk, H. (2014). Hubungan antara memori organisasi dan perilaku inovatif karyawan. Makara Hubs-Asia, 8 (3), 77-88.

Ford, C.M. (2000) Creative development in creativity theory. Academy of Management Review, 25, 284-289.

Georgsdottir, A.S. and Getz, I. (2004) How flexibility facilitates innovation and ways to manage it in organizations. Creativity \& Innovation Management, 13 (3), 166-175.

Hayes, A.F. (2012). Process: A versatile computational tool for observed variable mediation, moderation, and conditional process modelling. ht t p : / / afhayes . com/public/ process2012.pdf.

Hofstede, G., \& Hofstede, G.J. (2005). Cultures and organizations: Software of the mind, revised and expanded (2nd ed.). New York: McGraw-Hill.

Indonesia, Undang-Undang tentang Sistem Jaminan Sosial Nasional, UU No. 40 Tahun 2000.

Janssen, O. (2000), “Job demands, perceptions of effort-reward fairness and perilaku kerja inovatif", Journal of Occupational and Organizational Psychology, 73(3), 287-302.

Kanter, R. (1985), "Suorting innovation and venture development in established companies", Journal of Business Venturing, 1(1), 47-60.

Kanter, M. R. (1988). When a thousand flowers bloom: Structural, collective and social conditions for innovation in organization. In B. M. Staw \& L. L. Cummings (Ed.). Research in Organizational Behavior, 10, 169-211. Greenwich: JAI Press.

Keller, R.T. (2001) Cross-functional project groups in research and new product development: diversity, communications, job stress and outcomes. Academy of Management Journal, 4, 546-555.

Luthans, F., Youssef, C. M., \& Avolio, B. J. (2007). Modal psikologis: Developing the human competitive edge (p. 3). Oxford: Oxford University Press.

Luthans, F., Youssef, C.M. and Rawski, S.L. (2011), "A tale of two paradigms: the impact of modal psikologis and reinforcing feedback on problem solving and innovation", Journal of Organizational Behavior Management, Vol. 31 No. 4, . 333-350.

Lv, Z., \& Xu, T. (2016). Psychological contract breach, high-performance work system and engagement: The mediated effect of person-organization fit. The International Journal of Human Resource Management. Advance online publication. doi:10. 
1080/09585192.2016.1194873

Martinez-Sánchez, A., Vela-Jiménez, M.J., Pérez-Pérez, M. And de-LuisCarnicer, P. (2011), "The dynamics of labour flexibility: relationship between employment type and innovativeness", Journal of Management Studies, 48(4), 715-736.

Oldham, G.R. and Cummings, A. (1996), "Employee creativity: personal and contextual factors at work, Academy of Management Journal, 39(3), 607634.

Paulus, P.B. (2000) Groups, teams and creativity: the creative potential of idea-generating groups. Alied Psychology: An international Review, 49, 237-262.

Preacher, K.J., \& Hayes, A.F. (2004). SPSS and SAS procedures for estimating indirect effects in simple mediation models. Behavior Research Methods, Instruments, and Computers 36, 717731. Doi: 10.3758/BF03206553.

Robbins, Stephen P., \& Timothy A. Judge (2015). Organizational Behaviour, 16 th ed. New Jersey: Perason Education

Sapyaprapa, S., Tuicomepee, A., \& Watakakosol, R. (2013). Validation of modal psikologis questionnaire in Thai employees. In The Asian Conference on Psychology and the Behavioral Sciences. 394-400.

Shalley, C. E., Zhou, J., \& Oldham, G. R. 2004. The effects of personal and contextual characteristics on creativity: Where should we go from here? Journal of Management, 30: 933-958.

Staw, B.M. (1990) An evolutionary aroach to creativity and innovation. In West and J.L. Farr (Eds), Innovation and Creativity at Work: Psychological and Organizational Strategies. Chichester: John Wiley Sons, Ltd.

Subramanian, A., \& Nilakanta, S. (1996). Organizational innovativeness: exploring the relationship between organizational determinants of innova- tions, types of innovations and measures of organizational performance. International Journal Management Science, 24 (6), 631-647. Van der Vegt, G.S. and Janss en, O. (2003) Joint impact of interdependence and group diversity on innovation. Journal of Management, 29(5), 729 -752.

Veenendaal, A., \& Bondarouk, T. (2015). Perceptions of HRM and their effect on dimensions of innovative work behavior: Evidence from a manufacturing firm. Management revue, 138160.

West, M.A. and Hirst, G. (2003) Cooperation and teamwork for innovation. In $\mathrm{M}$. A. West., D. Tjosvold, and K.G. Smith (eds.): International Handbook of Organizational Teamwork and Cooperative Working. Chichester: John Wiley Sons, Ltd., 297-319.

Wojtczuk-Turek, A., \& Turek, D. (2015). Innovative behavior in the workplace: The role of Fleksibilitas SDM, individual flexibility and modal psikologis: the case of Poland. European Journal of Innovation Management, 18(3), 397-419.

Wright, P.M., McMahan, G.C. and McWilliams, A. (1994) Human resources and sustained competitive advantage: A resource-based perspective. International Journal of Human Resource Management, 5(2), 301-26.

Wright, P.M. and Snell, S.A. (1998), "Toward a unifying framework for exploring fit and flexibility in strategic human resource management", Academy of Management Review, 23(4), 756772.

Wright, P. M., Dunford, B. B., \& Snell, S. A. (2001). Human resources and the resource based view of the firm. Journal of management, 27(6), 701721.

Ziyae, B., Mobaraki, M. H., \& Saeediyoun, M. (2015). The effect of modal psikologis on innovation in information techo logy. Journal of Global Entrepreneur ship Research, 5(1), 1-12. 